\title{
Corrigendum to "Modelling of Coupled Cross-Flow/In-Line Vortex- Induced Vibrations Using Double Duffing and Van Der Pol Oscillators” [Ocean Eng. 53 (2012) 83-97]
}

\author{
Narakorn Srinil* \& Hossein Zanganeh \\ Department of Naval Architecture \& Marine Engineering, University of Strathclyde, \\ Henry Dyer Building, Glasgow G4 0LZ, Scotland, UK
}

The authors regret that there is a small typological error of the empirical constant $b_{1}$ in Eq. (19). The correct $b_{1}$ value - which has been considered in numerical simulations - is equal to 0.00234 instead of 0.0045 .

The authors would like to apologise for any inconvenience caused.

*Corresponding author: narakorn.srinil@strath.ac.uk; tel. +44 1415483463; fax +44 1415522879 